\title{
An Experimental Investigation for Seepage-Induced Instability of Confined Broken Mudstones with Consideration of Mass Loss
}

\author{
Luzhen Wang, ${ }^{1}$ Zhanqing Chen, ${ }^{2}$ and Hailing Kong ${ }^{1}$ \\ ${ }^{1}$ Civil Engineering Department, Yancheng Institute of Technology, Yancheng, Jiangsu 224051, China \\ ${ }^{2}$ State Key Laboratory for Geomechanics and Deep Underground Engineering, China University of Mining and Technology, \\ Xuzhou, Jiangsu 221116, China \\ Correspondence should be addressed to Hailing Kong; hailkong@126.com
}

Received 5 June 2017; Accepted 20 August 2017; Published 27 September 2017

Academic Editor: Qinghui Jiang

Copyright (C) 2017 Luzhen Wang et al. This is an open access article distributed under the Creative Commons Attribution License, which permits unrestricted use, distribution, and reproduction in any medium, provided the original work is properly cited.

To study and prevent water-mud-outburst disasters of tectonic fracture zones in geotechnical engineering, we tested seepage stability of confined broken mudstones with consideration of mass loss using syringe seepage method and a self-designed seepage testing system, obtained the variation laws of seepage instable duration, total mass loss, and mass loss rate of broken mudstones under different pressure gradients and Talbol power exponents (simplified as Talbol hereafter), and explained their instable seepage behaviors. The results showed that the mass loss is the internal cause of seepage-induced instability of broken rocks and pressure gradient is the external cause, and the persistent migration and loss of particles result in progressive failure process, while the large enough pressure gradient causes sudden overall instability. The seepage instable duration shortens with pressure gradient increasing, with the longest and shortest duration at Talbol of 0.5 and 0.1 , respectively. In general, mass loss increases with pressure gradient increasing and with Talbol decreasing. Mass loss rate increases with pressure gradient increasing but shows no monotonic changes with Talbol. Their expressions can be used to establish dynamic model in the further seepage stability researches.

\section{Introduction}

Geotechnical engineering projects involving tectonic fracture zones such as mining, slopping, excavating, and tunnel construction face issues of seepage from broken rocks which have high porosity and permeability, as well as complex porous and fracture structures. Their particle edges are easily broken under pressure and fine particles are prone to migrate under seepage. Under certain seepage pressure, fine particles in broken rocks will migrate and run off together with water, leading to increased rock porosity, enhanced permeability, and conversion of water flow from seepage into pipe flow, leading to seepage-induced instability. Therefore, we believe that unstable seepage behavior induced by mass loss of the broken rocks is an important reason for dynamic disasters such as water and mud outburst in the geotechnical engineering projects involving tectonic fracture zones.

The crushing of broken rocks during the loading is the primary cause for particles migration and is affected by many factors [1-4], such as particle shape, soil type, compaction effort [5-7], applied stress, initial grading of the tested soils [8], the artificial crushable material [9], changes in particle mixture [10], the complex shape in physics and geometry [11], and the geological framework [12]. In addition, the impact of seepage on rearrangements and migration of particles in confined broken rocks cannot be ignored. Many methods have been used to monitor seepage flow in broken rocks and investigate seepage properties [13-18] including stresscontrolling method and porosity-controlling method. Liu et al. [19] measured the permeability coefficients of sandstone, shale, and coal under three different types of axial compressions and described their confidence intervals. Ma et al. $[20,21]$ studied the permeability characteristics of broken shale, mudstone, and coal of four single particle sizes and analyzed the influence of seepage velocity, axial stress, and seepage pressure differences on permeability coefficient of broken rocks with different particle sizes. Furthermore, the porosity-controlling method could be used to measure the seepage velocity, permeability, and non-Darcy flow $\beta$ factor of broken rocks. Sun et al. [22] reported laws of permeability 
characteristics related to the load and particle diameter. Huang et al. [23] studied the relationships between the particle porosity and permeability parameters and found that the relationships could fit power functions and permeability parameters were related to the loading history. Miao et al. [24] discussed the deviation factor in Darcy flow and established a dimensionless dynamic model for the nonlinear seepage of broken rock mass. Wang et al. [25] studied the relationships between permeability parameters and porosity in two different loading histories and considered the influence of loading path on the permeability parameters of broken coal samples. Kong et al. [26] tested the permeability of crushed gangues with six different particle sizes during compaction using a crushed-rock compaction permeation apparatus and a self-designed seepage circuit and analyzed the relationships between seepage velocity, permeability, or non-Darcy $\beta$ factor and the porosity, particle size, or distribution. Ma et al. $[27,28]$ tested crushed mudstone, limestone, and sandstone specimens and found that the porosity, particle crushing, and seepage properties of crushed rocks were not only related to axial displacement, grain diameter size, and mixture sizes, but also related to the style of arrangement.

With the above research foundation about the crush and seepage of broken rocks, the loss of fine particles that migrate with water flow has become a hot point in academia. Kenney and Lau [29] considered that soil was comprised by soil skeleton and large number of fine loose particles movable among pores of soil skeleton in seepage process and measured the loss of movable fine particles using grading curves. Fox et al. [30] used the pans to collect sediment load and measured stream bank erosion due to ground water seepage with consideration of the bank pore water pressure and found that the quantity of mass loss was dependent on the type of seepage. Midgley et al. [31] measured soil-water pressures, seepage rate, and sediment concentration and found that seepage flow rate and corresponding erosion rate were proportional to hydraulic gradient. Sterpi [32] and Cividini and Gioda [33] considered the influence of seepage on the migration of movable fine particle and established empirical formulas between the mass loss of fine particles and pressure gradient or time. Ma et al. [28] studied the permeability of crushed mudstones and pointed out that the washed-away muds due to water seepage are the main reason for weight lost in mudstone samples. Yu et al. [34] experimentally studied the seepage characteristics of cemented broken mudstone and analyzed the influence of cementing material on the fine particles migration and mass loss.

Furthermore, scholars explored seepage-induced instability mechanism with consideration of mass loss, and they believed in the fact that the seepage-induced instability was seepage changing into pipe flow because the fine particles could be easily rushed away. Some emphasized the factor of seepage pressure in different projects, including foundation excavation [35-37], dam extrusion fracture zones [38, 39], tunnel construction [40], and coal mine [41, 42]. And they also pointed out that pressure gradient had greater effect on the loss of fine particles [43-45]. Some others may pay more attention to other factors, such as fine particles' content or size distribution $[34,46]$, confining pressure or triaxial pressure $[46,47]$, cementing material [34], and the emission of sand [48]. Meanwhile, they also discussed the influences of the above factors on seepage-induced instability and concluded that they were the important factors affecting seepage upheaval into pipe flow.

Our team $[25,26,49,50]$ have previously studied water outburst of collapse columns using a self-designed seepage system and tested the seepage characteristics of coal, coal gangue, sandstone, and mudstone under different pressure gradients using steady seepage test method. The experimental observations revealed a hydraulic breakdown phenomenon. In other words, turbid liquid flew out the broken rock samples at the moment when instable seepage occurred, indicating that the fine particles migration and loss occurred during the test.

The mass migration and loss is one of the major causes for seepage-induced instability of broken rocks. In addition, seepage stability of broken rocks is also affected by their diameter and packing mode as well as seepage pressure. If the gravel particles in broken rocks are properly distributed and orderly arranged and are in a tight structure form, the penetration ability of broken rocks is weak. However, when seepage pressure increases, the penetration ability of broken rocks will increase. Under the combined effects of these two factors, the particles inside broken rocks undergo an evolution process of migration and loss. Under different distribution of broken rock diameter and seepage pressure, seepage instable duration and mass loss will be significantly different.

In this paper, we analyzed the variation law of seepage instable duration and mass loss of broken rocks with consideration of particles migration and explored the instable seepage behavior of broken rocks under various seepage pressures and different diameter distribution, with the hope to provide an experimental basis for prediction and control of water and mud outburst in geotechnical engineering projects involving tectonic fracture zones.

\section{Experiment Principles and Methods}

2.1. Experimental System. Figure 1 shows the self-designed seepage test system of broken rocks with variable mass. It is composed of five subsystems, namely, (1) the seepage pressure loading and control subsystem, (2) particle-migrationachievable seepage subsystem, (3) fine particles collection subsystem, (4) axial load loading and displacement control subsystem, and (5) data acquisition and analysis subsystem. Among them, the seepage pressure loading and control subsystem, particle-migration-achievable seepage subsystem and fine particles collection subsystem are the core components of the test system.

The seepage pressure loading and control subsystem could load pressure using either syringe seepage mode or pump station mode based on users' needs. The pump station mode could directly achieve sample penetration with a metering pump. However, the method could cause pressure fluctuation and is unable to achieve long time constant pressure loading. The syringe seepage mode [51] uses oil and water as energy transfer medium in the upper and lower 


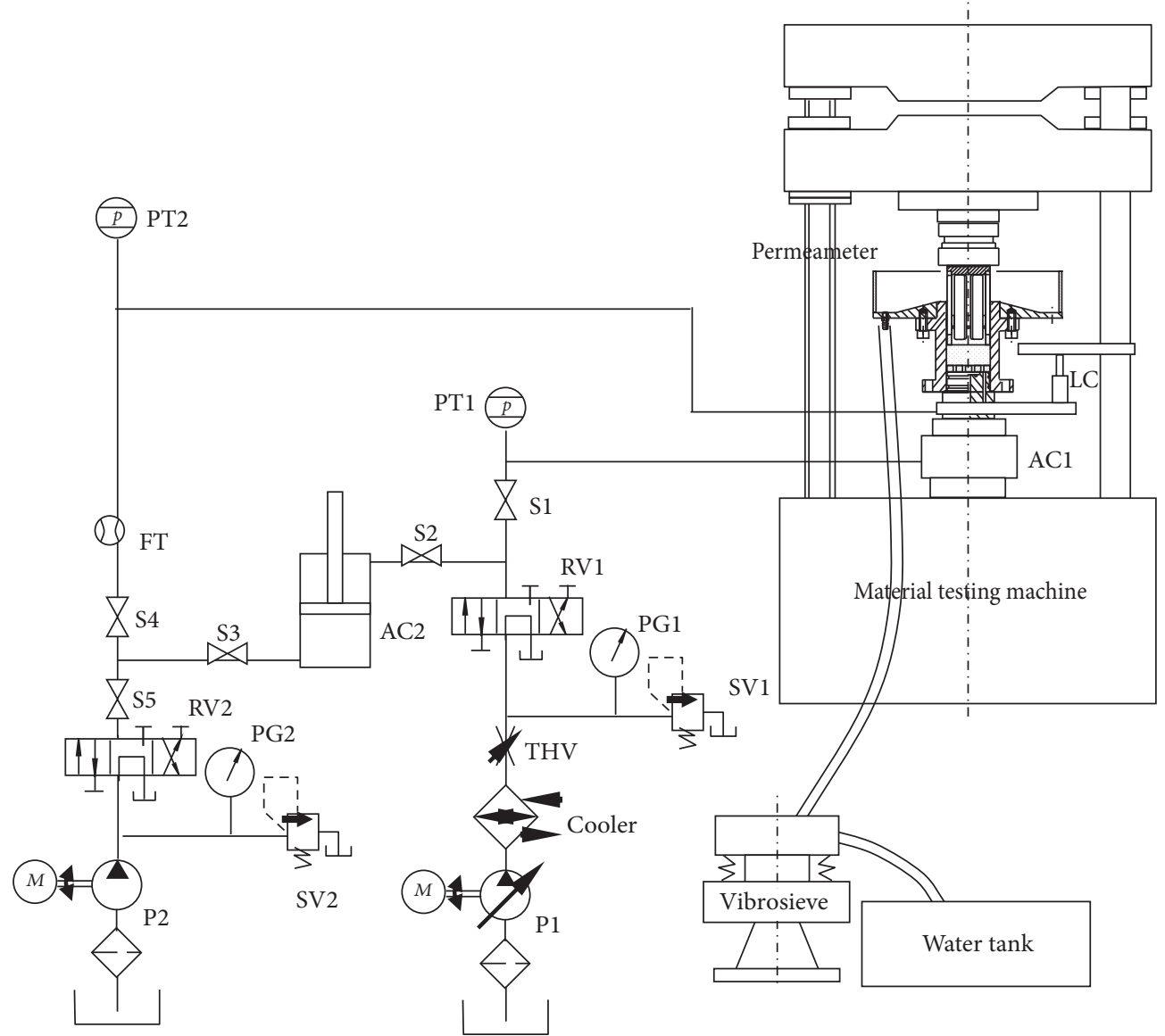

FIGURE 1: Schematic of the test system.

chambers of the double-acting hydraulic cylinder piston, respectively. Use of hydraulic oil makes it easy to control pressure while water in the lower chamber is easy to seep. In addition, throttle valve (THV), spill valve (SV1), and reversal valve (RV1) are placed in the pipelines of the variable piston pump (P1) and the upper chamber of the doubleacting hydraulic cylinder piston to achieve precise control of hydraulic oil flow and pressure.

In this study, we used the syringe seepage method to deliver adjustable, stable seepage pressure to the bottom of the rock sample. In detail, (1) open the shut-off valves S2, S3, and S5, close the shut-off valves S1 and S4, and turn on the metering pump P2 to inject water to the lower chamber of the double-acting hydraulic cylinder AC2; (2) after completion of injection, close the shut-off valve S5, open shut-off valve S4, and turn on the variable piston pump P1. The hydraulic oil pumped out by P1 flows in turn through the cooler, throttle valve THV, reversing valve RV1, and shut-off valve S2 into the upper chamber of the double-acting hydraulic cylinder AC2, pushing the piston rod moving downward. The piston rod then further drives water in the lower chamber of the double-acting hydraulic cylinder AC2 passing in turn through the shut-off valves S3 and S4, flow transducer FT, and permeameter; (3) once the water in the lower chamber of the double-acting hydraulic cylinder AC2 is exhausted, the experiment is temporarily stopped; (4) turn on the metering pump P2 to inject water into the lower chamber and repeat (2) and (3) till finishing the experiment.

The particle-migration-achievable seepage subsystem is a permeameter shown in Figure 2. The permeameter consists of baseboard, cylinder, piston, overflow tank and trays, and the like. The unique design of the piston and overflow tank allows particles to move freely.

Fine particles collection subsystem adopts filtration method to conduct the mixture of water and fine particles from the tray to vibrosieve through the hose. The filtrated fine particles are manually collected, dried, and weighted.

The axial load loading and displacement control subsystem uses variable piston pump P1 to provide pressure to the single-acting hydraulic cylinders $\mathrm{ACl}$, push the piston rod move upward, and load pressure to broken rock samples under the displacement control mode, making them be compressed and deformed.

The data acquisition and analysis subsystem consists of the pressure transducer PT, flow transducer FT, data acquisition instrument, PC, and so on and is used for realtime acquisition of seepage pressure and flow during the test. 


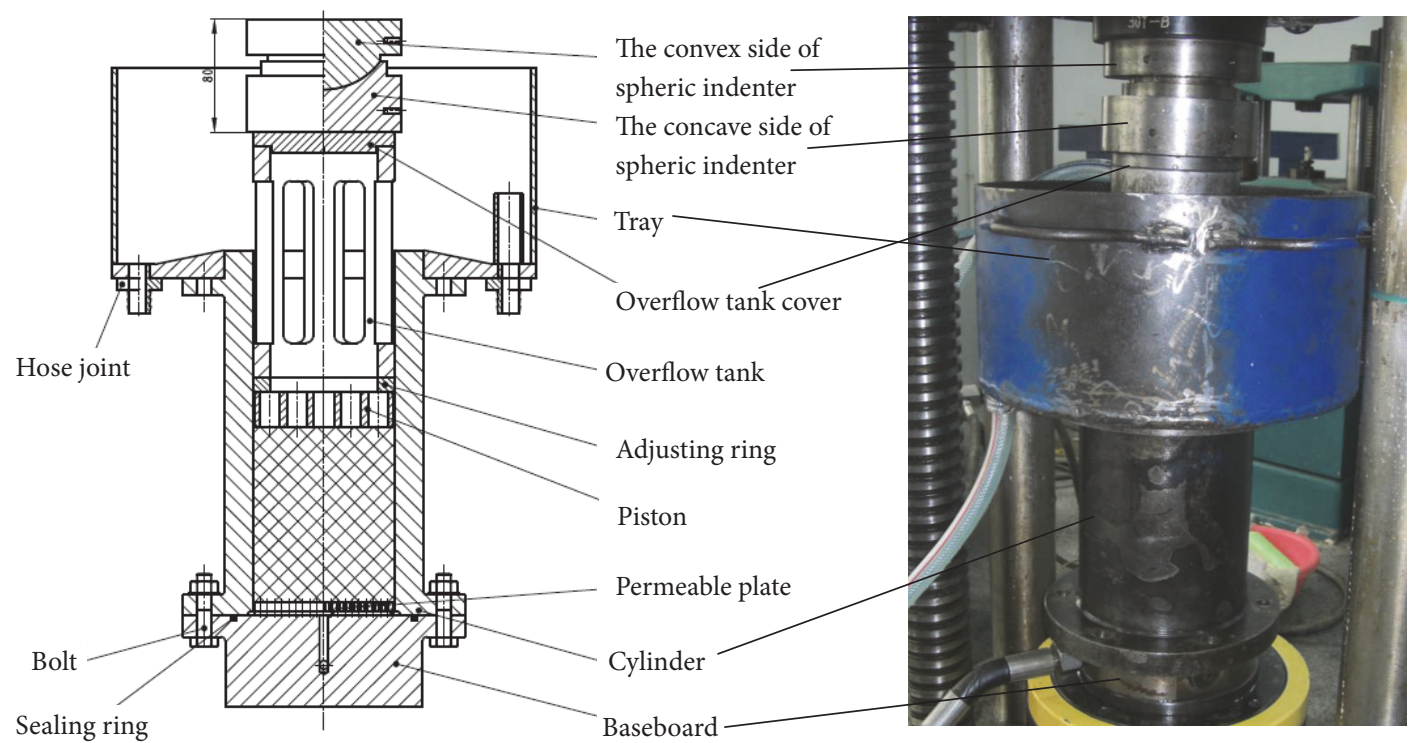

Figure 2: Permeameter.

TABLE 1: Mass (g) distribution of particles with different Talbols.

\begin{tabular}{cccccccccc}
\hline \multirow{2}{*}{ Mass (g) } & & \multicolumn{7}{c}{ Eight different particles sizes (mm) } \\
& & $0 \sim 2.5$ & $2.5 \sim 5$ & $5 \sim 8$ & $8 \sim 10$ & $10 \sim 12$ & $12 \sim 15$ & $15 \sim 20$ & $20 \sim 25$ \\
\hline \multirow{6}{*}{ Talbol } & 0.1 & 1588.7 & 114.0 & 81.9 & 40.3 & 33.6 & 41.9 & 55.5 & 44.1 \\
& 0.2 & 1261.9 & 187.6 & 142.9 & 72.7 & 61.8 & 78.8 & 106.9 \\
& 0.3 & 1002.4 & 231.7 & 186.9 & 98.4 & 85.4 & 111.1 & 154.7 & 129.5 \\
& 0.4 & 796.2 & 254.4 & 217.3 & 118.4 & 104.9 & 139.2 & 198.8 & 170.8 \\
& 0.5 & 632.5 & 262.0 & 236.9 & 133.5 & 120.7 & 163.6 & 239.7 & 211.1 \\
& 0.6 & 502.4 & 259.1 & 248.1 & 144.6 & 133.4 & 184.5 & 277.3 & 250.6 \\
& 0.7 & 399.1 & 249.2 & 252.6 & 152.3 & 143.4 & 202.3 & 312.0 & 289.2 \\
& 0.8 & 317.0 & 234.9 & 251.9 & 157.1 & 150.9 & 217.3 & 343.9 & 327.0 \\
& 0.9 & 251.8 & 218.1 & 247.4 & 159.5 & 156.3 & 229.8 & 373.2 & 363.9 \\
& 1.0 & 200.0 & 200.0 & 240.0 & 160.0 & 160.0 & 240.0 & 400.0 & 400.0 \\
\hline
\end{tabular}

2.2. Experimental Design and Methods. Tectonic fracture zones of the geotechnical engineering after long-term weathering contain very high clay content. Thus, we used mudstones as the experimental material. These mudstones were fractionated prior to experiment by sieving as particles with size of $0 \sim 2.5 \mathrm{~mm}, 2.5 \sim 5 \mathrm{~mm}, 5 \sim 8 \mathrm{~mm}, 8 \sim 10 \mathrm{~mm}, 10 \sim 12 \mathrm{~mm}$, $12 \sim 15 \mathrm{~mm}, 15 \sim 20 \mathrm{~mm}$, and 20 25 mm, respectively. A total of $2000 \mathrm{~g}$ of mudstones were packed into the barrel cylinder of the permeameter at the ratio defined using Talbol continuous gradation formula

$$
\frac{M_{d}}{M_{t}}=\left(\frac{d}{D}\right)^{n} \times 100 \%
$$

where $M_{d}$ is the mass of broken stone when diameter is less than or equal to $d, \mathrm{~g} ; M_{t}$ is the total mass of broken stones, $\mathrm{g}$; $d$ is the diameter of the broken stones, $\mathrm{mm}$; $D$ is the maximum diameter of the broken stones, $\mathrm{mm} ; n$ is the Talbol power exponent (simplified as Talbol hereafter) and taken as 0.1,
$0.2,0.3,0.4,0.5,0.6,0.7,0.8,0.9$, and 1.0 , respectively. The mass partition corresponding to the particles with various diameters is shown in Table 1, and the natural packing height of testing samples with different Talbols is listed in Table 2.

From Tables 1 and 2 it is clear that the greater the Talbol, $n$, the higher the content of mudstones with greater diameter and the higher the natural packing height of the sample. On the contrary, the smaller the Talbol, $n$, the higher the content of mudstones with smaller size and the lower the natural packing height of the sample.

Before seepage, all samples are compressed to the same height of $120 \mathrm{~mm}$. During the test, seepage water pressure at the bottom of the broken rock samples, $p$, could be obtained by the opening pressure, $P$ (shown on pressure gage PG1), of the spill valve SV1, inner diameter of the double-acting hydraulic cylinder, $d_{1}$, and the diameter of piston rod, $d_{2}$,

$$
\frac{p}{P}=1-\left(\frac{d_{2}}{d_{1}}\right)^{2} \text {. }
$$


TABLE 2: The natural packing height ( $\mathrm{mm}$ ) of tested samples with different Talbols.

\begin{tabular}{|c|c|c|c|c|c|c|c|c|c|c|}
\hline Talbol power exponent & 0.1 & 0.2 & 0.3 & 0.4 & 0.5 & 0.6 & 0.7 & 0.8 & 0.9 & 1.0 \\
\hline Natural packing height $(\mathrm{mm})$ & 147 & 150 & 153 & 155 & 156 & 160 & 163 & 166 & 170 & 172 \\
\hline
\end{tabular}

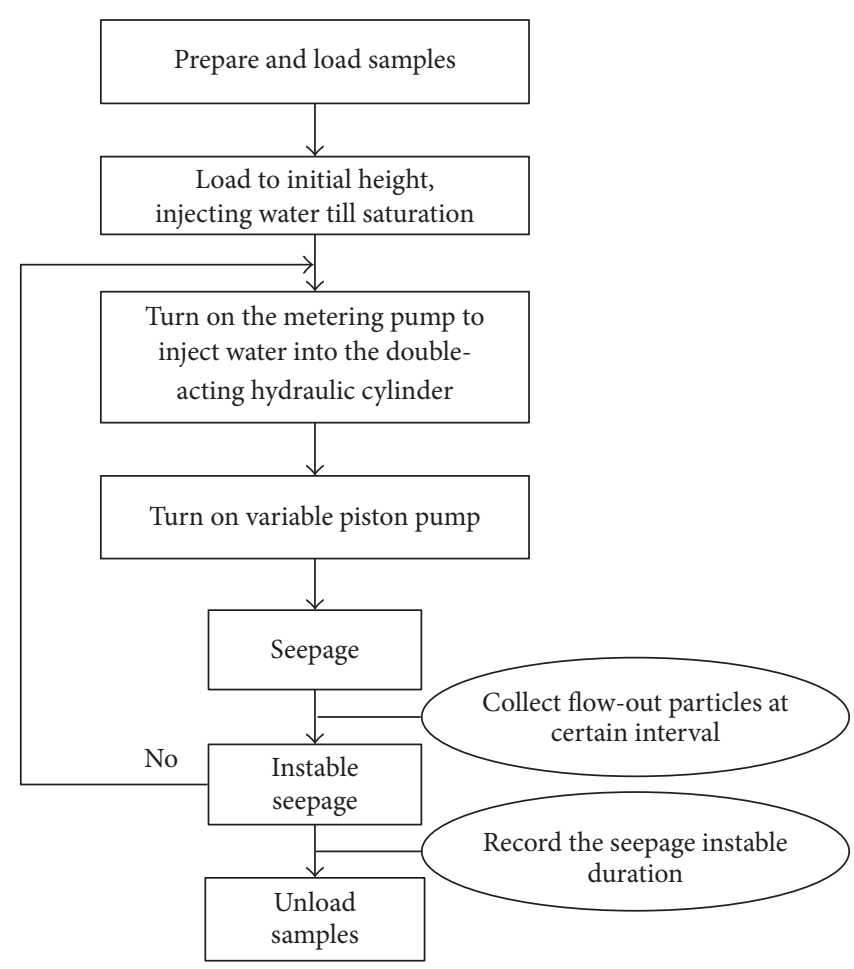

FIgURE 3: Flow chart of the experiment.

During the experiment, $p$ was taken as $3,4,5,6$, and $7 \mathrm{MPa}$, respectively. Because the top of the broken rock samples is connected to the atmosphere, if ignoring pipeline losses, $p$ is the difference in the seepage pressure at top and bottom of the broken sample and used to calculate the corresponding pressure gradient $G_{P}$, which was $25,33,42,50$, and $58 \mathrm{MPa} / \mathrm{m}$.

A steady state seepage method was used in the experiment. During the seepage process, the pressure gradient is constant. When dynamic phenomena such as slurry discharge from the permeameter occurred, sample was considered to undergo seepage upheaval. In other words, seepage was transformed into pipe flow, inducing instability. Thus, the test was ended. Seepage instable duration, $T$, was recorded and the total mass loss, $m_{p}$, during the seepage instable process was collected to calculate the mass loss rate, $m_{p}^{\prime}$,

$$
m_{p}^{\prime}=\frac{m_{p}}{T} .
$$

In this study, a total of 50 groups of tests in combination of 10 different Talbols and 5 different pressure gradients were conducted with 3 repeats for each combination. The results were expressed as the average of three repeats and further analyzed.
2.3. Experimental Process. Figure 3 illustrates seepageinduced instability experimental process of the confined broken mudstones with the consideration of mass loss.

The experimental process included the following steps: (1) debug the test system and put the mixed broken rock samples into the open permeameter; (2) compress the broken rock samples using variable piston pump to the initial height; (3) inject water into the samples for 30 minutes to ensure that samples were water-saturated; (4) load seepage pressure on the bottom of the rock sample using the syringe seepage method and collect the flow-out particles at a certain interval; (5) conduct the test until the seepage-induced instability occurs and record the seepage instable duration; and (6) finish the test and unload the samples in time.

\section{Results and Analysis}

Seepage instable duration, $T$, total mass loss, $m_{p}$, as well as mass loss rate, $m_{p}^{\prime}$, of the 150 tested samples under different Talbols, $n$, and pressure gradients, $G_{p}$, were obtained and analyzed below.

3.1. Variation Law of the Seepage Instable Duration. Figure 4(a) shows the variation law of seepage instable duration, 


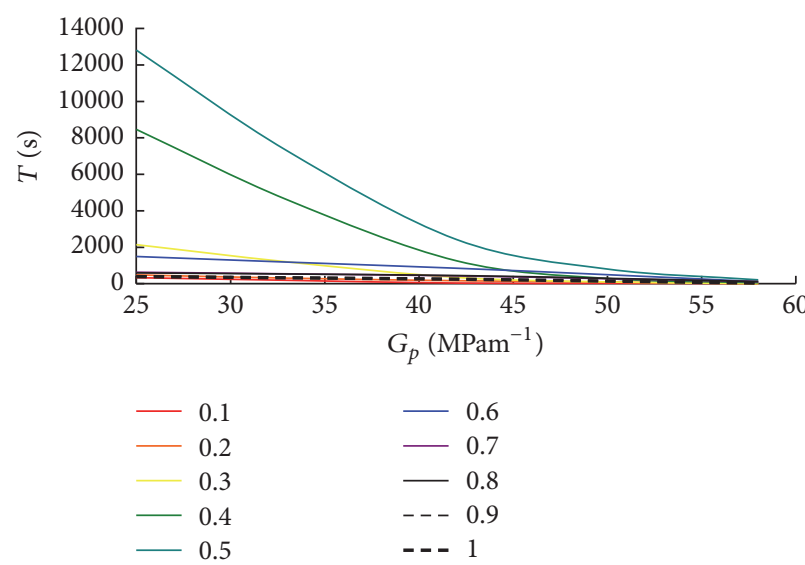

(a)

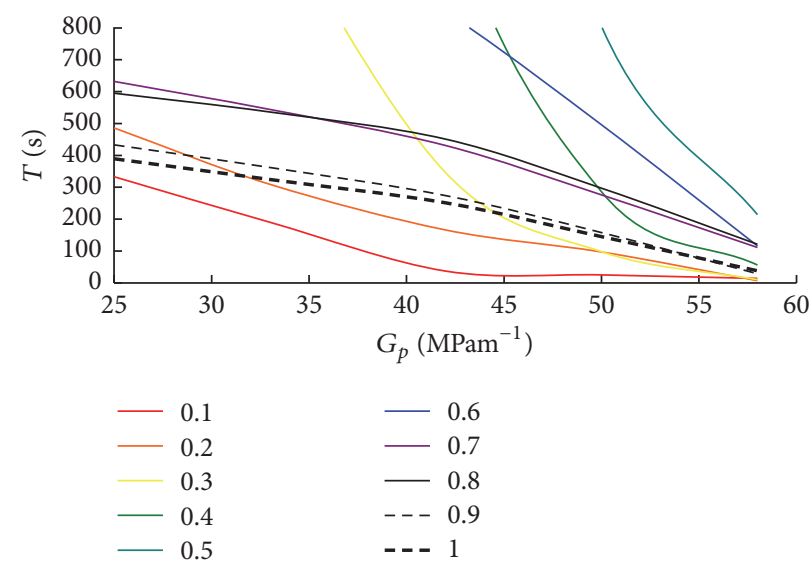

(b)

FIGURE 4: Variation of seepage instable duration with pressure gradient.

$T$, of the tested samples under 10 different Talbols at pressure gradient, $G_{p}$, and Figure $4(\mathrm{~b})$ is the enlarged view of partial Figure 4(a) when duration is less than $800 \mathrm{~s}$.

As shown from Figure 4, under the same pressure gradient, seepage instable duration is the longest at Talbol of 0.5. After sample compaction, the internal porous structure of the sample is arranged properly, particles of different sizes extrude toward each other and close up, showing no apparent seepage channels, which enable the sample with strong water blocking ability. By contrast, the duration is the shortest at Talbol of 0.1. The sample contains as high as $85 \%$ easy-to-migrate fine particles and is less stable. At the instable seepage stage, the sample shows a "mesh-like" destruction. The seepage instable duration of samples with Talbols of 0.9 and 1.0 is relatively short, about 2 -fold of the shortest duration. In samples with Talbols of 0.9 and 1.0, large particles are significantly more than fine particles. But after compaction, fine particles cannot effectively fill the gaps. Thus, the samples have loose internal structure and large porous space. Under seepage pressure, they are prone to subject to instable seepage.

Figure 4 also shows that at each Talbol, the seepage instable duration shortens with pressure gradient increasing. When pressure gradient increases from $25 \mathrm{MPa} / \mathrm{m}$ to $58 \mathrm{MPa} / \mathrm{m}$, the seepage instable duration of samples with Talbol of 0.3 drops the most, by $99.5 \%$, while that of samples with Talbol of 0.8 drops the least, by about $80 \%$. The relationship of seepage instable duration to pressure gradient is expressed as logarithmic fitting functions, as shown in Table 3 and could be uniformly expressed as

$$
T=-a \ln \left(G_{p}\right)+b
$$

where coefficients $a$ and $b$ are the function of Talbol, $n$, and could be expressed as

$$
\begin{array}{r}
a=660.90+17567.16 e^{-2((n-0.464) / 0.121)^{2},} \\
\\
\left(R^{2}=0.9886\right),
\end{array}
$$

TABLE 3: Functional relationship of seepage instable duration with pressure gradient and their correlation coefficients.

\begin{tabular}{lcc}
\hline Talbol & Fitting function & Correlation coefficient \\
\hline 0.1 & $T=-397.74 \ln \left(G_{p}\right)+1585.5$ & 0.9156 \\
0.2 & $T=-561.31 \ln \left(G_{p}\right)+2281.4$ & 0.9952 \\
0.3 & $T=-2636.3 \ln \left(G_{p}\right)+10475$ & 0.9499 \\
0.4 & $T=-10406 \ln \left(G_{p}\right)+41281$ & 0.9425 \\
0.5 & $T=-15527 \ln \left(G_{p}\right)+61927$ & 0.9562 \\
0.6 & $T=-1606.4 \ln \left(G_{p}\right)+6748.7$ & 0.9709 \\
0.7 & $T=-603.26 \ln \left(G_{p}\right)+2621.9$ & 0.9349 \\
0.8 & $T=-540.04 \ln \left(G_{p}\right)+2390.1$ & 0.8855 \\
0.9 & $T=-466.46 \ln \left(G_{p}\right)+1970.2$ & 0.9383 \\
1.0 & $T=-406.421 \ln \left(G_{p}\right)+1727.1$ & 0.9411 \\
\hline
\end{tabular}

$$
\begin{array}{r}
b=2741.69+69611.39 e^{-2((n-0.465) / 0.121)^{2}}, \\
\left(R^{2}=0.9891\right) .
\end{array}
$$

3.2. Variation Law of the Mass Loss. Figure 5(a) shows the variation laws of mass loss, $m_{p}$, with pressure gradient, $G_{p}$, of samples with 10 kinds of Talbols during seepage instable process and Figure $5(\mathrm{~b})$ is the enlarged view of samples with mass loss $<140 \mathrm{~g}$ in Figure 5(a).

Figure 5 shows that, under same pressure gradient, such as $G_{p}=25 \mathrm{MPa} / \mathrm{m}$, mass loss of samples with Talbol of 0.4 is the highest, $544.8 \mathrm{~g}$, while that of samples with Talbols of 0.9 and 1.0 is the least, $39 \mathrm{~g}$ and $45.2 \mathrm{~g}$, respectively. When $G_{p}=58 \mathrm{MPa} / \mathrm{m}$, the mass loss of samples with Talbol of 0.1 is the most, $919 \mathrm{~g}$, while that of samples with Talbols of 0.9 and 1.0 is least, $123.6 \mathrm{~g}$ and $133.2 \mathrm{~g}$, respectively. The figure also shows that the greater the Talbol, the less the amount of the easily migrated particles with diameter $<5 \mathrm{~mm}$ and the less the mass loss.

The content of easily migrated particles accounts for up to $85 \%$ of total particles in samples with Talbol of 0.1 . These fine 


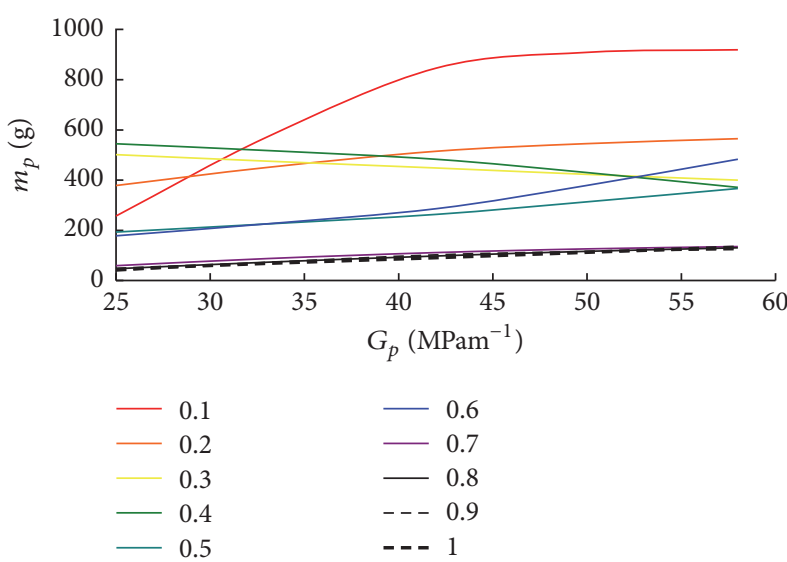

(a)

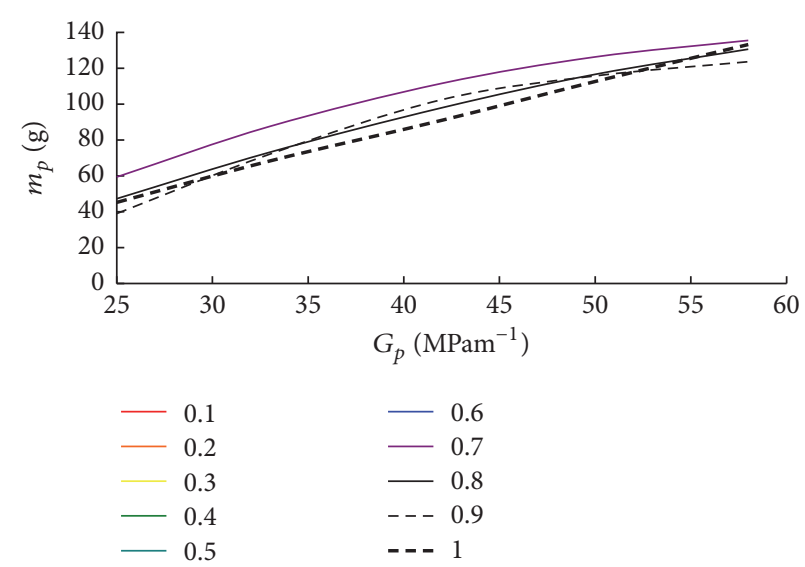

(b)

FIGURE 5: Variation of mass loss with pressure gradient.

particles are densely compacted and present in consolidation. When the pressure gradient is small, the seepage pressure is small and the migration of particles in the seepage channel is blocked. Thus, mass loss is significantly less. Therefore, when $G_{p}=25 \mathrm{MPa} / \mathrm{m}$, the mass loss of samples with Talbol of 0.1 is less than that of samples with Talbols of $0.2,0.3$, and 0.4 . When the pressure gradient is large, seepage pressure is high, the water carrying capacity increases. With more fine particles migrating and flowing away, the flow rate of the seepage channel under high seepage pressure increases, leading to significant mass loss. Therefore, at relatively high pressure gradient, mass loss of samples with Talbol of 0.1 is significantly higher than that of other samples.

With pressure gradient increasing, particles are subjected to higher seepage pressure and have increased migration ability under the action of water erosion, thus mass loss is more evident. The reasons for the decreased mass loss of samples with Talbols of 0.3 and 0.4 may be related to the distribution of inner porous structure and the spatial distribution of seepage channels. The migration of migratable particles is blocked in the seepage channels, leading to reduced mass loss.

Under the same Talbol, the relation of mass loss to pressure gradient is fitted with a logarithmic function, as shown in Table 4 and could be uniformly expressed as

$$
m_{p}=a \ln \left(G_{p}\right)+b,
$$

where coefficients $a$ and $b$ are the functions of Talbol, $n$, and could be expressed as the fourth-order polynomial fitting formulas:

$$
\begin{aligned}
a= & 28164 n^{4}-71080 n^{3}+62039 n^{2}-21459 n+2452.5, \\
b= & -97339 n^{4}+248396 n^{3}-218802 n^{2}+75511 n \\
& -8084.2, \quad\left(R^{2}=0.8472\right) .
\end{aligned}
$$

TABLE 4: Functional relationship of mass loss with pressure gradient and their correlation coefficients.

\begin{tabular}{lcc}
\hline Talbol & Fitting function & Correlation coefficient \\
\hline 0.1 & $m_{p}=821.41 \ln \left(G_{p}\right)-2326.5$ & 0.9283 \\
0.2 & $m_{p}=226.4 \ln \left(G_{p}\right)-343.42$ & 0.9860 \\
0.3 & $m_{p}=-120.15 \ln \left(G_{p}\right)+892.48$ & 0.9884 \\
0.4 & $m_{p}=-199.48 \ln \left(G_{p}\right)+1204.5$ & 0.9181 \\
0.5 & $m_{p}=201.04 \ln \left(G_{p}\right)-468.28$ & 0.9459 \\
0.6 & $m_{p}=349.75 \ln \left(G_{p}\right)-978.27$ & 0.9174 \\
0.7 & $m_{p}=91.882 \ln \left(G_{p}\right)-234.51$ & 0.9941 \\
0.8 & $m_{p}=99.921 \ln \left(G_{p}\right)-275.08$ & 0.9994 \\
0.9 & $m_{p}=103.23 \ln \left(G_{p}\right)-289.83$ & 0.9814 \\
1.0 & $m_{p}=103.5 \ln \left(G_{p}\right)-291.35$ & 0.9884 \\
\hline
\end{tabular}

3.3. Variation Law of the Mass Loss Rate. Table 5 shows the mass loss rate of samples with 10 different Talbols under 5 pressure gradients at instable seepage. Figure 6(a) shows the variation laws in mass loss rates, $m_{p}^{\prime}$, of samples with 10 different Talbols with pressure gradient, $G_{p}$, and Figure 6(b) is the enlarged view of samples with mass loss rate $<7 \mathrm{~g} \mathrm{~s}^{-1}$ in Figure 6(a).

From Table 5 it is clear that when $G_{p}=25 \mathrm{MPa} / \mathrm{m}$, the mass loss rate is the lowest for samples with Talbol of 0.5 and the highest for samples with Talbol of 0.2; the latter is 51-fold of the former. When $G_{p}=58 \mathrm{MPa} / \mathrm{m}$, the mass loss rate is the lowest for samples with Talbol of 0.8 and the highest for samples with Talbol of 0.2 ; the latter is 75 -fold of the former. Because the sample mass loss rate is closely related to the mass loss and seepage instable duration, with Talbol increasing, the variation law of mass loss is not always consistent with that of seepage instable duration.

As can be seen from Table 5 and Figure 6, at the same Talbol, the mass loss rate increases with the pressure gradient increasing, showing the greatest increase in samples with 
TABLE 5: Mass loss rate $\left(\mathrm{g} \mathrm{s}^{-1}\right)$ of tested samples at different Talbols and pressure gradients.

\begin{tabular}{|c|c|c|c|c|c|c|}
\hline \multirow{2}{*}{\multicolumn{2}{|c|}{ Mass loss rate $\left(\mathrm{g} \mathrm{s}^{-1}\right)$}} & \multicolumn{5}{|c|}{ Pressure gradient $G_{P}\left(\mathrm{Mpa} \mathrm{m}^{-1}\right)$} \\
\hline & & 25 & 33 & 42 & 50 & 58 \\
\hline \multirow{10}{*}{ Talbol } & 0.1 & 0.772 & 3.006 & 22.87 & 36.35 & 65.64 \\
\hline & 0.2 & 0.779 & 1.458 & 3.102 & 5.623 & 80.71 \\
\hline & 0.3 & 0.234 & 0.396 & 1.296 & 4.316 & 40.00 \\
\hline & 0.4 & 0.064 & 0.112 & 0.385 & 1.504 & 6.629 \\
\hline & 0.5 & 0.015 & 0.031 & 0.109 & 0.390 & 1.714 \\
\hline & 0.6 & 0.119 & 0.190 & 0.337 & 0.764 & 4.166 \\
\hline & 0.7 & 0.094 & 0.161 & 0.259 & 0.458 & 1.221 \\
\hline & 0.8 & 0.079 & 0.137 & 0.217 & 0.393 & 1.079 \\
\hline & 0.9 & 0.090 & 0.199 & 0.374 & 0.732 & 4.262 \\
\hline & 1.0 & 0.116 & 0.211 & 0.363 & 0.777 & 3.505 \\
\hline
\end{tabular}

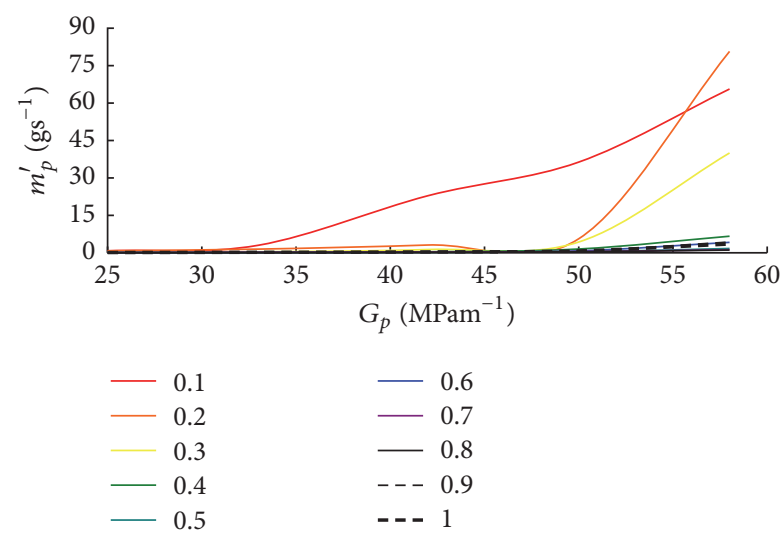

(a)
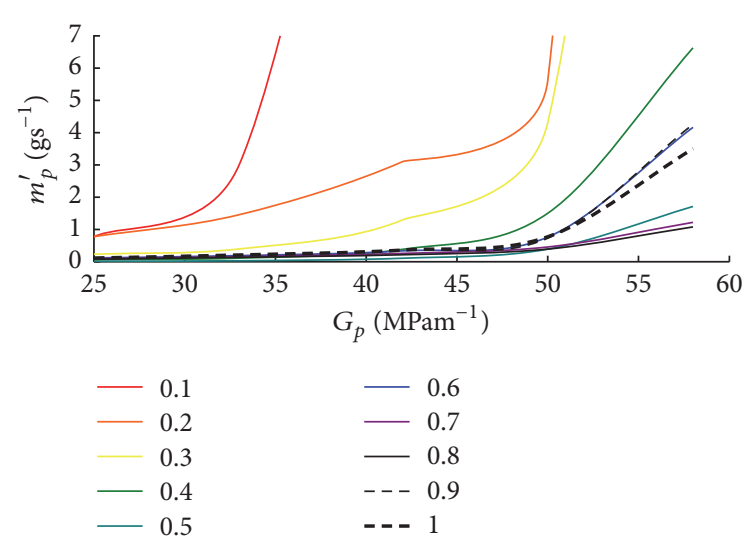

(b)

FiguRE 6: Variation of mass loss rate with pressure gradient.

TABLE 6: Functional relationship of mass loss rate with pressure gradient and their correlation coefficients.

\begin{tabular}{llc}
\hline Talbol & Fitting function & Correlation coefficient \\
\hline 0.1 & $m_{p}^{\prime}=0.0341 e^{0.1377 G_{p}}$ & 0.9409 \\
0.2 & $m_{p}^{\prime}=0.0217 e^{0.1275 G_{p}}$ & 0.8709 \\
0.3 & $m_{p}^{\prime}=0.0033 e^{0.1523 G_{p}}$ & 0.9435 \\
0.4 & $m_{p}^{\prime}=0.0013 e^{0.1428 G_{p}}$ & 0.9763 \\
0.5 & $m_{p}^{\prime}=0.0003 e^{0.1444 G_{p}}$ & 0.9858 \\
0.6 & $m_{p}^{\prime}=0.0068 e^{0.102 G_{p}}$ & 0.9179 \\
0.7 & $m_{p}^{\prime}=0.0134 e^{0.0742 G_{p}}$ & 0.9719 \\
0.8 & $m_{p}^{\prime}=0.0109 e^{0.0754 G_{p}}$ & 0.9687 \\
0.9 & $m_{p}^{\prime}=0.0051 e^{0.1082 G_{p}}$ & 0.9417 \\
1.0 & $m_{p}^{\prime}=0.0082 e^{0.0974 G_{p}}$ & 0.9414 \\
\hline
\end{tabular}

Talbol of 0.3 and the smallest increase in samples with Talbol of 0.7 .

The relationship of mass loss rate to pressure gradient is expressed as exponential functions, as shown in Table 6, and could be uniformly expressed as

$$
m_{p}^{\prime}=a e^{b G_{p}}
$$

where coefficients $a$ and $b$ are the functions of Talbol, $n$, and can be expressed as

$$
\begin{aligned}
a=-0.3058 n^{3}+0.5882 n^{2}-0.341 n+0.0641, & \\
& \left(R^{2}=0.8946\right), \\
b=0.7584 n^{3}-1.2447 n^{2}+0.5013 n+0.0903, & \\
& \left(R^{2}=0.7593\right) .
\end{aligned}
$$

From the above research, the Talbol power exponent and the pressure gradient both impact on the seepage instable duration, total mass loss, and mass loss rate and interact with each other. The relationships of all these parameters as described in formulas (4) to (9) are the most important components to establish dynamic model in the further researches on seepage stability. Therefore, we analyzed the relative errors between experimental data and the theoretical values calculated using the fitting functions. The average relative error of total mass loss is about $20.9 \%$, and the minimum one is only $0.045 \%$. The relative errors of seepage instable duration and mass loss rate are higher. Considering the granular characteristics and complex pore structures in the broken rocks, discreteness is inevitable in laboratory 


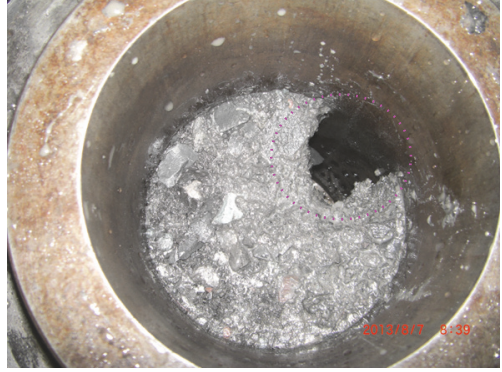

(a) The type 1 water outburst channel

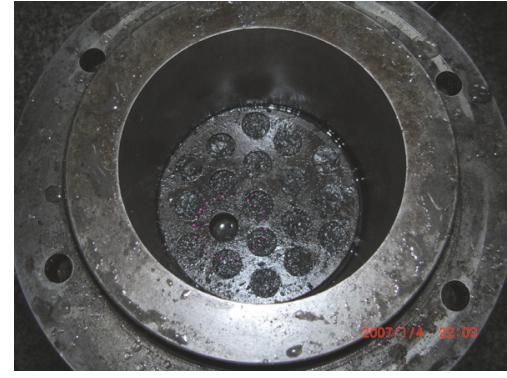

(b) The type 2 water outburst channel

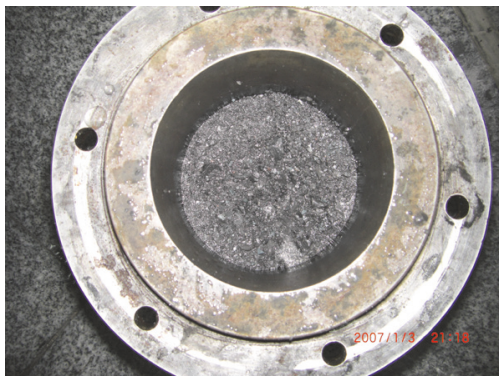

(c) The type 3 water outburst channel

FIGURE 7: Outburst channel types at instable seepage stage.

tests. Therefore, the fitting functions are viable to establish a dynamic model with consideration of the mass conservation equation, pore compression equation, and so on.

\section{Analysis of Instable Seepage Behavior}

The study showed that mass loss is the internal cause for seepage-induced instability of broken rocks and the pressure gradient is the external cause. Due to action of pressure gradient, water seeps into the pores of the broken rocks. Its corrosion and erosion actions along with the abrasive action of the original fine particles lead to the materials near the pore walls of the broken rocks free from the rocks, forming the secondary fine particles. Small portion of the fine particles are dissolved in water, forming a slurry, some portion of the fine particles are suspended in the slurry, forming a suspension, and other parts of the fine particles are deposited on the pore wall. Under action of pressure gradient, the suspension migrates in broken rock pores and continues to corrode and erode the pore wall, while the precipitate is mixed with the abrasive materials and continues to erode the pore wall. Under the joint and circulatory actions of corrosion, erosion, and abrasion, fine particles are continuously carried out from the broken rocks, resulting in continuous mass loss and porosity increase. When the mass loss reaches certain stage, water outburst channels are formed in the porous structure, the pattern of liquid flow changes from seepage into pipe flow, leading to instable seepage, or water and mud dynamic disasters.

During the experiment, it was found that there are three types of water outburst channels at instable seepage stage, as shown in Figure 7. In the first case, water outburst channel is located in the irregular cavity in the outer cylindrical surface of the rock sample. In the second case, water outburst channel is located in the irregular cavity inside the rock sample. In the third case, the water outburst panel is composed of several fine cavities inside the rock sample.

The first type of water outburst channel is more common, in which the solid body formed by the broken mudstone is at glue-like state and has good water control ability. In addition, the resistance is the least at the contact area of the outer cylindrical surface of the testing sample with the cavity wall of permeameter, easily forming water outburst channels. Once the dynamic water rushes into the channel, fine particles will be flashed out, carried away, and lost under the action of cuneiform splitting and expanding of water flow. With further expansion of the channel and particles migration and loss, instable seepage occurs along the channel.

The second type of water outburst channel is commonly seen at high seepage pressure. Inside the column, there are weakened areas not tightly filled with small particles. When high pressure water acts on the cylindrical pore gaps in the form of dynamic load, the water permeable pore gaps in these weakened areas are gradually opened up under the wedge effect of high pressure water, leading to muddy mass loss and increased porous permeability. Once forming water outburst channel in the column, dynamic water will rush into the cylinder, flashing out large number of particles and leading to mass migration and loss. Subsequently, water will rush upward along the pipe flow formed due to the extension of the weak area.

In the formation process of the first and second types of water outburst channels, samples undergo drastic seepage changes, showing an obvious dynamic pressure effect. At this period, inside cavity of the permeameter will sound, along with cylinder vibration, splashing out partial particles with diameter of $0 \sim 8 \mathrm{~mm}$ from the overflow tank, which is the hydraulic breakdown phenomenon mentioned in the literature [49].

The third outburst channel is commonly seen in samples with very high content of particles with low diameter (0 $8 \mathrm{~mm}$ ). Such samples have loose internal structure. Under the action of seepage pressure, the "mesh-like" water outburst channels are rapidly formed. At this moment, seepage form of the sample is closer to Darcy flow. The seepage instable duration due to this type of water outburst channel is generally shorter. After the migration and loss of a large number of particles with water flow, the sink of whole column body is observed within a short period of time, which happens to have the same view with the literature [44].

Above all, the seepage-induced instability shows two possibilities. One is a progressive failure process because of the persistent migration and loss of particles. The other one is a sudden overall instability because of the large enough pressure gradient and existing migration channels. 


\section{Conclusions}

In order to investigate and prevent water and mudstone outburst disasters in geotechnical engineering tectonic fracture zones, a self-designed seepage test system of broken rocks with variable mass was used to test seepage instability of mudstones and explore the effects of pressure gradient and Talbol on seepage instable duration, total mass loss, and mass loss rate during the whole seepage instable process. In addition, the seepage-induced instability behavior of broken mudstones was investigated with consideration of mass loss. The following conclusions are reached:

(1) The seepage instable duration becomes shorter with pressure gradient increasing, showing the greatest drop at Talbol of 0.3 and smallest decline at Talbol of 0.8 . At the same pressure gradient, seepage instable duration is the longest at Talbol of 0.5 and shortest at Talbol of 0.1; the former is $197 \%$ of the latter.

(2) Total mass loss increases with the pressure gradient increasing except at Talbols of 0.3 and 0.4 , which slightly decreases. Under the same pressure gradient, the overall mass loss increases as Talbol reducing. Mass loss is significantly higher when Talbol is 0.1 than others at a relatively high pressure gradient but appears to be significantly less than others at low pressure gradient.

(3) Mass loss rate increases with pressure gradient increasing with the largest increase at Talbol of 0.3 and the smallest increase at Talbol of 0.7 .

(4) Mass loss is the internal cause of seepage-induced instability in broken rocks and the pressure gradient is the external cause. When mass loss reaches a certain degree, water outburst channel in the porous structure is formed, and the pattern of liquid flow changes from seepage to pipe flow, leading to instable seepage and inducing water and mud outburst dynamic disasters.

(5) The water outburst channel at instable seepage stage is divided into three kinds, located in irregular tube caves of the outer cylindrical surface of the rock sample, irregular tube caves inside the rock sample, and several small, fine tube caves inside the rock samples, respectively. Different types of water outburst channels lead to different seepage instable duration and different total mass loss and demonstrate different dynamic pressure effects. The reason of the seepageinduced instability is also different.

(6) The seepage instable duration and total mass loss both can be expressed as a logarithmic function of pressure gradient, while the mass loss rate can be expressed as exponential function of pressure gradient. The coefficients of these functions are affected by Talbol. The fitting functions are viable to establish a dynamic model.

(7) The expressions of seepage instable duration, total mass loss, and mass loss rate become an important part of establishing dynamic model in the further seepage stability researches. Maybe the microscopic mechanism of particle migration can be further studied by introducing the microscopic method, but not only the observation of experimental phenomena.

\section{Symbols}

a: Coefficient $(-)$

b: Coefficient $(-)$

$d$ : Diameter of the broken stones (L)

$D$ : Maximum diameter of the broken stones

(L)

$d_{1}$ : Inner diameter of the double-acting

hydraulic cylinder (L)

$d_{2}$ : Diameter of piston $\operatorname{rod}(\mathrm{L})$

$G_{p}$ : Pressure gradient $\left(\mathrm{ML}^{-2} \mathrm{~T}^{-2}\right)$

$m_{p}:$ Total mass loss (M)

$m_{p}^{\prime}$ : Mass loss rate $\left(\mathrm{MT}^{-1}\right)$

$M_{d}$ : Mass of broken stones when diameter is less than or equal to $d(\mathrm{M})$

$M_{t}$ : Total mass of broken stones (M)

$n$ : Talbol power exponent (simplified as Talbol) (-)

$p$ : Seepage pressure at the bottom of the broken rock samples $\left(\mathrm{ML}^{-1} \mathrm{~T}^{-2}\right)$

$P$ : Opening pressure of the pressure relief valve SV1 $\left(\mathrm{ML}^{-1} \mathrm{~T}^{-2}\right)$

$T$ : $\quad$ Seepage instable duration (T).

\section{Conflicts of Interest}

The authors declare that there are no conflicts of interest regarding the publication of this paper.

\section{Acknowledgments}

This work was supported by the National Natural Science Fund (11502229), the Natural Science Foundation of Jiangsu Province of China (BK20160433), the Outstanding Young Backbone Teacher of QingLan Project in Jiangsu Province, Jiangsu Government Scholarship for Overseas Studies, and the Program of Outstanding Young Scholars in Yancheng Institute of Technology.

\section{References}

[1] B. O. Hardin, "Crushing of soil particles," Journal of Geotechnical Engineering, vol. 111, no. 10, pp. 1177-1192, 1985.

[2] P. V. Lade, J. A. Yamamuro, and P. A. Bopp, "Significance of particle crushing in granular materials," Journal of Geotechnical Engineering, vol. 122, no. 4, article no. 9927, pp. 309-316, 1996.

[3] S. Lobo-Guerrero and L. E. Vallejo, "Discrete element method evaluation of granular crushing under direct shear test conditions," Journal of Geotechnical and Geoenvironmental Engineering, vol. 131, no. 10, pp. 1295-1300, 2005.

[4] F. Casini and G. M. B. Viggiani, "Experimental investigation of the evolution of grading of an artificial material with crushable 
grains under different loading conditions," in Proceedings of the 5th International Symposium on Deformation Characteristics of Geomaterials, pp. 957-964, Seoul, Korea, 2011.

[5] I. H. Hamdani, "Optimum moisture content for compacting soils: one-point method," Journal of Irrigation and Drainage Engineering, vol. 109, no. 2, pp. 232-237, 1983.

[6] L. R. Blotz, C. H. Benson, and G. P. Boutwell, "Estimating optimum water content and maximum dry unit weight for compacted clays," Journal of Geotechnical and Geoenvironmental Engineering, vol. 124, no. 9, pp. 907-912, 1998.

[7] G.-C. Cho, J. Dodds, and J. C. Santamarina, "Particle shape effects on packing density, stiffness, and strength: natural and crushed sands," Journal of Geotechnical and Geoenvironmental Engineering, vol. 132, no. 5, pp. 591-602, 2006.

[8] M. R. Coop, K. K. Sorensen, T. B. Freitas, and G. Georgoutsos, "Particle breakage during shearing of a carbonate sand," Geotechnique, vol. 54, no. 3, pp. 157-163, 2004.

[9] F. Casini, G. M. B. Viggiani, and S. M. Springman, "Breakage of an artificial crushable material under loading," Granular Matter, vol. 15, no. 5, pp. 661-673, 2013.

[10] M. Jamei, H. Guiras, Y. Chtourou, A. Kallel, E. Romero, and I. Georgopoulos, "Water retention properties of perlite as a material with crushable soft particles," Engineering Geology, vol. 122, no. 3-4, pp. 261-271, 2011.

[11] D. Wu, Y. Hu, and X. Fan, "Visual simulation for granular rocks crush in virtual environment based on fractal geometry," Simulation Modelling Practice and Theory, vol. 17, no. 7, pp. 12541266, 2009.

[12] A. Aydin, R. I. Borja, and P. Eichhubl, "Geological and mathematical framework for failure modes in granular rock," Journal of Structural Geology, vol. 28, no. 1, pp. 83-98, 2006.

[13] K. Kogure, "Experimental study on permeability of crushed rock," Memoirs of the Defense Academy, Japan, vol. 16, no. 4, pp. 149-154, 1976.

[14] M. D. Zoback and J. D. Byerlee, "Note on the deformational behavior and permeability of crushed granite," International Journal of Rock Mechanics \& Mining Sciences \& Geomechanics Abstracts, vol. 13, no. 10, pp. 291-294, 1976.

[15] G. N. K. Pradip and P. Venkataraman, "Non-Darcy converging flow through coarse granular media," Journal of the Institution of Engineers (India): Civil Engineering Division, vol. 76, pp. 6-11, 1995.

[16] J. Legrand, "Revisited analysis of pressure drop in flow through crushed rocks," Journal of Hydraulic Engineering, vol. 128, no. 11, pp. 1027-1031, 2002.

[17] I. Engelhardt and S. Finsterle, "Thermal-hydraulic experiments with bentonite/crushed rock mixtures and estimation of effective parameters by inverse modeling," Applied Clay Science, vol. 23, no. 1-4, pp. 111-120, 2003.

[18] X. X. Miao, W. Q. Liu, and Z. Q. Chen, Seepage Theory of Mining Strata, Science Press, Beijing, China, 2004.

[19] W. Q. Liu, X. D. Fei, and J. N. Fang, "Rules for confidence intervals of permeability coefficients for water flow in overbroken rock mass," International Journal of Mining Science and Technology, vol. 22, no. 1, pp. 29-33, 2012.

[20] Z. G. Ma, X. X. Miao, X. H. Li, G. L. Guo, and X. S. Shi, "Permeability of broken shale," Journal of Mining Safety Engineering, vol. 24, no. 3, pp. 260-264, 2007.

[21] Z. G. Ma, X. X. Miao, F. Zhang, and Y. S. Li, "Experimental study into permeability of broken mudstone," Journal of China University of Mining \& Technology, vol. 17, no. 2, pp. 147-151, 2007.
[22] M. G. Sun, T. Z. Li, X. W. Huang, and R. H. Chen, "Penetrating properties of non-Darcy flow in fragmentized rock," Journal of Anhui University of Science and Technology (Natural Science), vol. 23, no. 2, pp. 11-13, 2003.

[23] X.-W. Huang, P. Tang, X.-X. Miao, and Z.-Q. Chen, "Testing study on seepage properties of broken sandstone," Yantu Lixue/Rock and Soil Mechanics, vol. 26, no. 9, pp. 1385-1388, 2005.

[24] X.-X. Miao, S.-C. Li, and Z.-Q. Chen, "Bifurcation and catastrophe of seepage flow system in broken rock," Mining Science and Technology, vol. 19, no. 1, pp. 1-7, 2009 (Chinese).

[25] L.-Z. Wang, Z.-Q. Chen, H.-L. Kong, and H.-D. Shen, "Experimental study of impact of loading history on permeability characteristics of broken coal with different grain size gradations," Yantu Lixue/Rock and Soil Mechanics, vol. 34, no. 5, pp. 13251330, 2013.

[26] H. L. Kong, Z. Q. Chen, L. Z. Wang, and H. D. Shen, "Experimental study on permeability of crushed gangues during compaction," International Journal of Mineral Processing, vol. 124, pp. 95-101, 2013.

[27] D. Ma, X. X. Miao, G. H. Jiang, H. B. Bai, and Z. Q. Chen, "An experimental investigation of permeability measurement of water flow in crushed rocks," Transport in Porous Media, vol. 105, no. 3, pp. 571-595, 2014.

[28] D. Ma, H. B. Bai, Z. Q. Chen, and H. Pu, "Effect of particle mixture on seepage properties of crushed mudstones," Transport in Porous Media, vol. 108, no. 2, pp. 257-277, 2015.

[29] T. C. Kenney and D. Lau, "Internal stability of granular filters," Canadian Geotechnical Journal, vol. 22, no. 2, pp. 215-225, 1985.

[30] G. A. Fox, G. V. Wilson, A. Simon, E. J. Langendoen, O. Akay, and J. W. Fuchs, "Measuring streambank erosion due to ground water seepage: correlation to bank pore water pressure, precipitation and stream stage," Earth Surface Processes and Landforms, vol. 32, no. 10, pp. 1558-1573, 2007.

[31] T. L. Midgley, G. A. Fox, G. V. Wilson, D. M. Heeren, E. J. Langendoen, and A. Simon, "Seepage-induced streambank erosion and instability: in situ constant-head experiments," Journal of Hydrologic Engineering, vol. 18, no. 10, pp. 1200-1210, 2013.

[32] D. Sterpi, "Effects of the erosion and transport of fine particles due to seepage flow," International Journal of Geomechanics, vol. 3, no. 1, pp. 111-122, 2003.

[33] A. Cividini and G. Gioda, "Finite-element approach to the erosion and transport of fine particles in granular soils," International Journal of Geomechanics, vol. 4, no. 3, pp. 191-198, 2004.

[34] B. Y. Yu, Z. Q. Chen, Y. Wu, S. B. Zhang, and L. L. Yu, "Experimental study on the seepage characteristics of cemented broken mudstone," Caikuang yu Anquan Gongcheng Xuebao/Journal of Mining and Safety Engineering, vol. 32, no. 5, pp. 853-858, 2015.

[35] Y.-H. Xia, S.-W. Bai, and C. Zhang, "Seepage deformation evaluation of foundation pit excavation of power-house of a hydro-project," Yantu Lixue/Rock and Soil Mechanics, vol. 28, no. 11, pp. 2435-2439, 2007.

[36] Q. Hu, D.-S. Ling, R.-P. Chen, Y.-M. Chen, and G.-W. Jia, "Research on deep foundation pit excavation due to seepage failure of soil," Yantu Lixue/Rock and Soil Mechanics, vol. 29, no. 11, pp. 2967-2972, 2008.

[37] J.-F. Chen and M.-G. Feng, "Study of anti-seepage measures for foundation pit based on saturated-unsaturated seepage theory," Yantu Lixue/Rock and Soil Mechanics, vol. 30, no. 5, pp. 14251430, 2009. 
[38] S.-R. Feng, H.-B. Zhao, Z.-M. Jiang, and X.-X. Zeng, "Experimental study on seepage failure characteristics of broken rock mass in dam foundation at left bank of Xiangjiaba Hydropower Project," Yantu Gongcheng Xuebao/Chinese Journal of Geotechnical Engineering, vol. 34, no. 4, pp. 600-605, 2012.

[39] H. B. Zhao, B. Jian, S. J. Wang, and Z. M. Jiang, "In-situ test of fractured rock mass with high pressure seepage in dam foundation," Yanshilixue Yu Gongcheng Xuebao/Chinese Journal of Rock Mechanics and Engineering, vol. 28, no. 11, pp. 22952300, 2009.

[40] X. J. Weng, Study on Inrush of Water And Mud Mechanism and Grouting Control Technology in Water-Rich Fault Fracture Zone of Tunnel, Shandong University, Jinan, China, 2014.

[41] W. P. Li, Q. M. Liu, and R. H. Sun, “Theoretical and experiment study on Vadose conversion of water inrush later occurred from structure broken zone," Coal Science and Technology, vol. 39, no. 11, pp. 10-13, 2011.

[42] W. Qiao, G. Hu, and W.-P. Li, "Experimental study on the conversion from seepage to flow of water inrush aroused by fault activation in fully mechanized top-coal caving," Caikuang yu Anquan Gongcheng Xuebao/Journal of Mining and Safety Engineering, vol. 30, no. 1, pp. 30-37, 2013.

[43] E. M. Palmeira, R. J. Fannin, and Y. P. Vaid, "A study on the behaviour of soil-geotextile systems in filtration tests," Canadian Geotechnical Journal, vol. 33, no. 6, pp. 899-912, 1996.

[44] S. S. Tomlinson and Y. P. Vaid, "Seepage forces and confining pressure effects on piping erosion," Canadian Geotechnical Journal, vol. 37, no. 1, pp. 1-13, 2000.

[45] R. A. Moffat and R. J. Fannin, "A large permeameter for study of internal stability in cohesionless soils," Geotechnical Testing Journal, vol. 29, no. 4, pp. 273-279, 2006.

[46] F. Bendahmane, D. Marot, and A. Alexis, "Experimental parametric study of suffusion and backward erosion," Journal of Geotechnical and Geoenvironmental Engineering, vol. 134, no. 1, pp. 57-67, 2008.

[47] K. S. Richards and K. R. Reddy, "True triaxial piping test apparatus for evaluation of piping potential in earth structures," Geotechnical Testing Journal, vol. 33, no. 1, 2010.

[48] J.-S. Chen, H.-Q. He, S. Wang, M.-M. Zeng, T. Wang, and W.-Z. He, "Analysis of piping sanding and flux of cohesionless soils," Yantu Lixue/Rock and Soil Mechanics, vol. 35, no. 3, pp. 623-630, 2014.

[49] L. Z. Wang, Z. Q. Chen, and H. D. Shen, "Experimental study on the type change of liquid flow in broken coal samples," Journal of Coal Science Engineering, vol. 19, no. 1, 2013.

[50] L. Z. Wang, Z. Q. Chen, H. L. Kong, and X. Y. Ni, "An experimental study of the influence of seepage pressure and initial porosity on variable mass seepage for broken mudstone," Caikuang yu Anquan Gongcheng Xuebao/Journal of Mining and Safety Engineering, vol. 31, no. 3, pp. 462-475, 2014.

[51] L. Z. Wang, H. L. Kong, Z. Q. Chen, B. She, Z. B. Cai, and G. L. Liu, A sustainable pressor osmosis system for rock seepage test, 2016, China: ZL201410031033.2. 

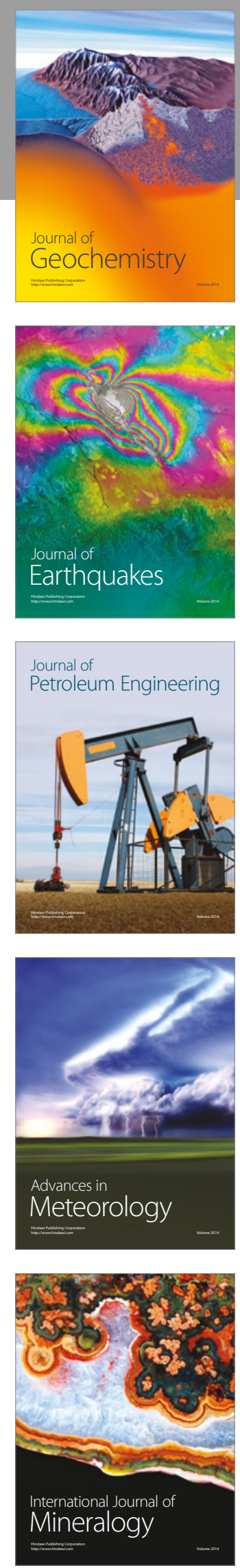
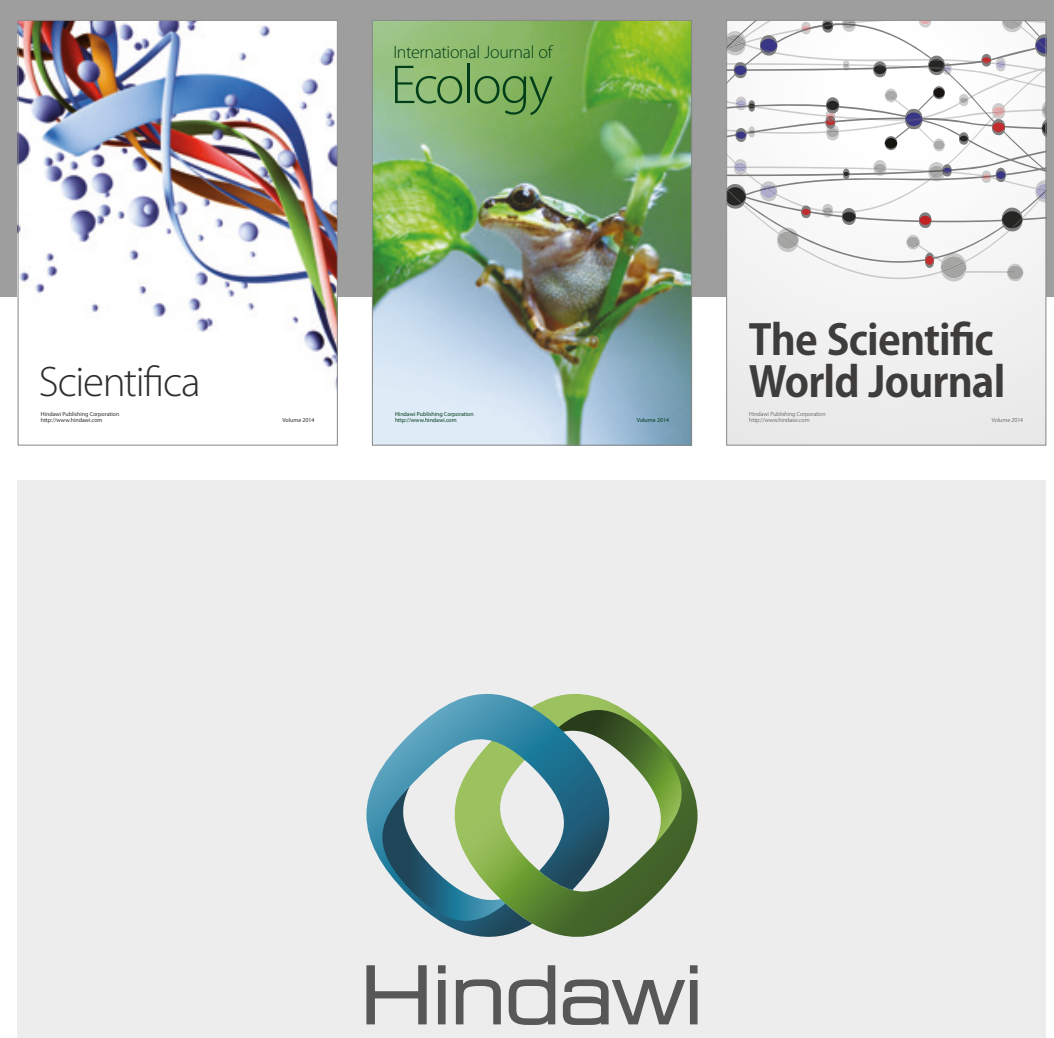

Submit your manuscripts at

https://www.hindawi.com
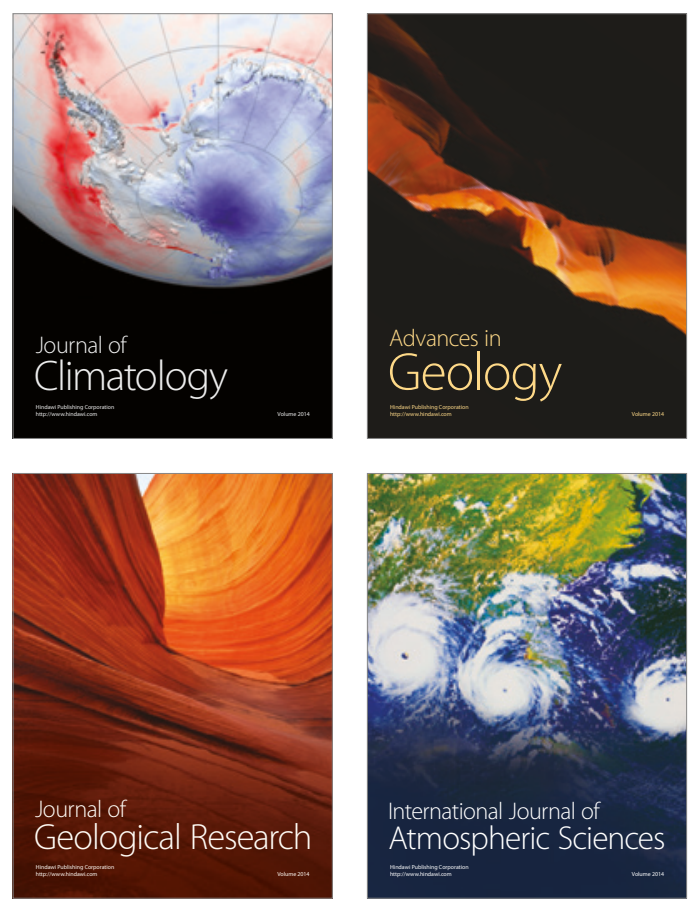

The Scientific

World Journal
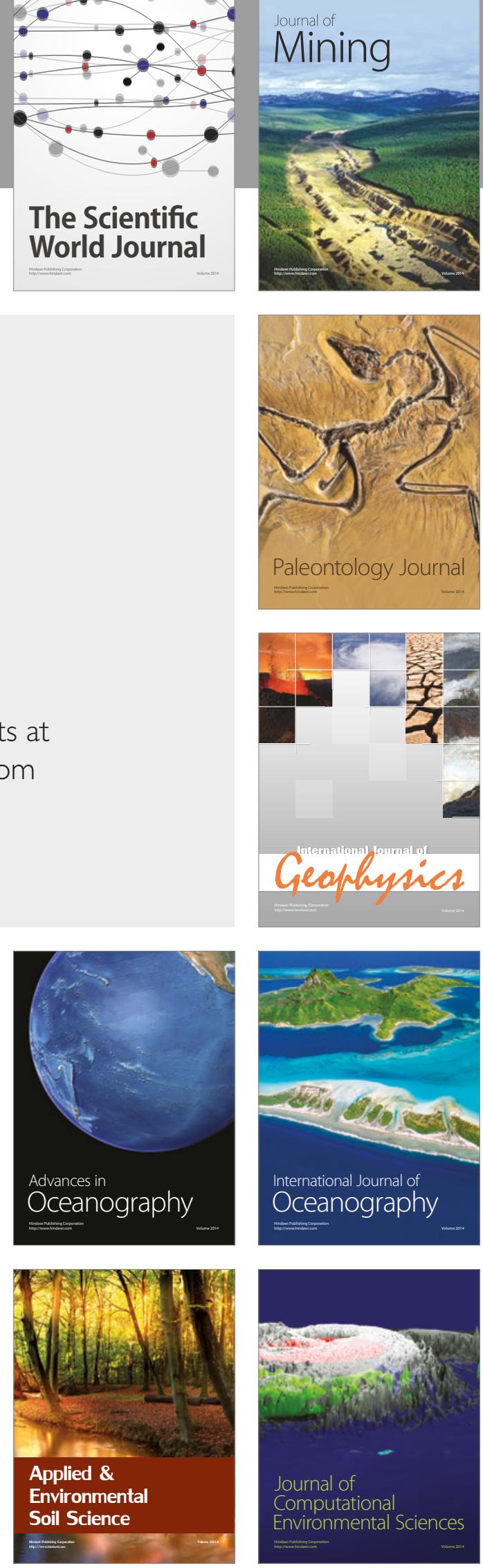